\title{
Intermittent hypoxia alleviates increased VEGF and pro-angiogenic potential in liver cancer cells
}

\author{
GANG DONG, XIA-HUI LIN, HUA-HUA LIU, DONG-MEI GAO, \\ JIE-FENG CUI, ZHENG-GANG REN and RONG-XIN CHEN \\ Liver Cancer Institute, Zhongshan Hospital, Fudan University and Key Laboratory of
Carcinogenesis and Cancer Invasion, Ministry of Education, Shanghai 200032, P.R. China
}

Received November 26, 2018; Accepted April 25, 2019

DOI: 10.3892/ol.2019.10486

\begin{abstract}
Vascular endothelial growth factor (VEGF) is an important angiogenic factor. The VEGF rebound induced by hypoxia following transarterial embolization/chemoembolization for primary liver cancer is associated with treatment failure and poor survival rates in patients. The present study investigated the ability of intermittent hypoxia to alleviate the acute hypoxia-induced increase of VEGF and decrease the pro-angiogenic potential of liver cancer cells. The liver cancer cells were exposed to normoxia, or acute or intermittent hypoxia, and the expression of VEGF was determined using reverse transcription-quantitative polymerase chain reaction analysis and western blotting. The pro-angiogenic effects of acute or intermittent hypoxia-exposed liver cancer cells on endothelial cells were assessed in vitro and in vivo. The expression of VEGF in the liver cancer cells exposed to intermittent hypoxia was significantly lower than that in cells exposed to acute hypoxia. Compared with conditioned medium (CM) from acute hypoxia-exposed liver cancer cells, the CM from intermittent hypoxia-exposed liver cancer cells showed markedly less promotion of proliferation and tube formation in endothelial cells. Activation of the reactive oxygen species (ROS)/NF- $\mathrm{kB} /$ hypoxia-inducible factor-1 $\alpha /$ VEGF signaling pathway was increased in the liver cancer cells exposed to acute hypoxia. Exposure to ROS scavenger $\mathrm{N}$-acetyl-cysteine or NF- $\mathrm{KB}$ inhibitor PDTC inhibited the activation of the above pathway and the expression of VEGF induced by acute hypoxia. The in vivo pro-angiogenic effects of intermittent hypoxia-exposed liver cancer cells on endothelial cells were significantly reduced compared with those of acute hypoxia-exposed liver cancer cells. Intermittent hypoxia may
\end{abstract}

Correspondence to: Dr Rong-Xin Chen, Liver Cancer Institute, Zhongshan Hospital, Fudan University and Key Laboratory of Carcinogenesis and Cancer Invasion, Ministry of Education, 180 Fenglin Road, Xuhui, Shanghai 200032, P.R. China

E-mail: chen.rongxin@zs-hospital.sh.cn

Key words: liver cancer, intermittent hypoxia, vascular endothelial growth factor, angiogenesis alleviate the acute hypoxia-induced increase of VEGF and decrease the pro-angiogenic potential of liver cancer cells, suggesting a novel treatment strategy.

\section{Introduction}

Primary liver cancer is one of the most common causes for cancer-associated mortality worldwide (1). Due to its nonspecific symptoms, the diagnosis of liver cancer is often made at an intermediate-advanced stage, rendering patients unsuitable for curative treatments (2). Transcatheter arterial embolization/chemoembolization (TAE/TACE) provides a modest survival benefit for patients with unresectable liver cancer (3), which limits hepatic arterial blood supply to liver cancer and exerts antitumor effects by inducing tumor ischemic hypoxia and necrosis (4). However, the results of TAE/TACE remain unsatisfactory, with local recurrence rates as high as $30-60 \%$ (4). Among the factors interfering with the effectiveness of TAE/TACE, a neoangiogenic reaction following treatment is frequently observed (5). In addition to inducing complete necrosis in small-sized liver cancer, TAE/TACE inevitably results in an acute hypoxic insult in the majority of liver cancer lesions (5). It is apparent that hypoxia-induced angiogenesis contributes to tumor regrowth (5-7). Of note, the stimulation of vascular endothelial growth factor (VEGF) following treatment has emerged as a negative factor affecting treatment efficacy and patient survival rates (8-12). Bevacizumab, an antibody targeting VEGF, can attenuate the increase in VEGF post-TACE and reduce neo-vessel formation detected using angiography $(13,14)$. However, the optimal embolic endpoint of TACE, which is correlated with the extent of hypoxia, has not been clarified. It has been reported that the embolization of tumor blood supply to a sub-stasis endpoint during TACE improves survival rates compared with embolization to a stasis endpoint (15), suggesting that the extent or patterns of embolization-induced hypoxia affect treatment outcomes. This prompted the hypothesis that the pattern of tumor hypoxia induction influences tumor progression.

In the present study, it was shown that intermittent hypoxia alleviated the acute hypoxia-induced increase of VEGF, and consequently decreased the pro-angiogenic potential of liver cancer; these findings suggest the potential use of a novel embolism strategy using TACE to induce intermittent hypoxia. 


\section{Materials and methods}

Reagents and antibodies. Monoclonal anti-hypoxia-inducible factor (HIF)- $1 \alpha$ antibody (cat. no. ab51608; Abcam), anti-VEGF antibody (cat. no. ab51745; Abcam), anti- $\beta$-actin antibody (cat. no. ab8224; Abcam), anti-P38 mitogen-activated protein kinase (MAPK) antibody (cat. no. ab31828; Abcam), anti-phosphorylated (p-)P38MAPK antibody (cat. no. ab4822; Abcam), monoclonal anti-Akt antibody (cat. no. ab8805; Abcam), anti-p-Akt antibody (cat. no. ab38449; Abcam),

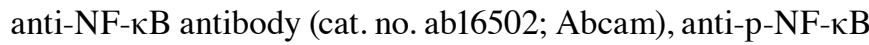
antibody (cat. no. 3033S; Cell Signaling Technology), anti-Src antibody (cat. no. 184Q20; Thermo Fisher Scientific, Inc.), anti-p-Src antibody (cat. no. 44-660G; Thermo Fisher Scientific, Inc.), anti-extracellular signal-regulated kinase (ERK)1/2 antibody (cat. no. 13-6200; Thermo Fisher Scientific, Inc.) and anti-p-ERK1/2 antibody (cat. no. 44-680G; Thermo Fisher Scientific, Inc.) were used for western blotting. $\mathrm{N}$-acetyl-cysteine (NAC), ammonium pyrrolidinedithiocarbamate (PDTC) and the reactive oxygen species (ROS) assay were purchased from Beyotime Institute of Biotechnology.

Cell culture and treatment. The HepG2 (ATCC) and Huh7 (Japanese Cancer Research Resources Bank) liver cancer cell lines and the EA.hy926 human umbilical vein cell line (ATCC) were maintained in Dulbecco's modified Eagle's medium (DMEM; Gibco; Thermo Fisher Scientific, Inc.) supplemented with $10 \%$ fetal bovine serum (Gibco; Thermo Fisher Scientific, Inc.) and $1 \%$ penicillin-streptomycin (Gibco; Thermo Fisher Scientific, Inc.) in a $5 \% \mathrm{CO}_{2}$ incubator at $37^{\circ} \mathrm{C}$. The $\mathrm{HepG} 2$ cell line is derived from hepatoblastoma. The cell lines were authenticated using short tandem repeat validation analysis. For acute hypoxia, the liver cancer cells were cultured under $1 \%$ oxygen for $48 \mathrm{~h}$. For intermittent hypoxia exposure, the cells were subjected to three cycles of hypoxia-reoxygenation comprising culture under $1 \%$ oxygen for $24 \mathrm{~h}$ followed by $21 \%$ oxygen for $24 \mathrm{~h}$, and finally under $1 \%$ oxygen for $48 \mathrm{~h}$.

Reverse transcription-quantitative polymerase chain reaction $(R T-q P C R)$ analysis. TRIzol ${ }^{\circledR}$ (Invitrogen; Thermo Fisher Scientific,Inc.) was used to extract the total cellular RNA, which was then reverse-transcribed into cDNA using a RevertAid First Strand cDNA Synthesis kit (Thermo Fisher Scientific, Inc.) in accordance with the manufacturer's instructions. The primers used were as follows: VEGF, 5'-CCAACTTCTGGG CTGTTCTC-3' (sense) and 5'-CCCCTCTCCTCTTCCTTC TC-3' (antisense); platelet-derived growth factor (PDGF), 5'-GATGATCTCCAACGCCTGCT-3' (sense) and 5'-TCT TCCACGAGCCAAGCTCT-3' (antisense); $\beta$-actin, 5'-CAT GTACGTTGCTATCCAGGC-3' (sense) and 5'-CTCCTTAAT GTCACGCACGAT-3' (antisense). FastStart Universal Probe Master (Roche Diagnostics) was used to amplify the resultant cDNA The thermocycling conditions were as follows: $50^{\circ} \mathrm{C}$ for $2 \mathrm{~min} ; 95^{\circ} \mathrm{C}$ for $10 \mathrm{~min} ; 40$ cycles of $95^{\circ} \mathrm{C}$ for $15 \mathrm{sec}$ and $60^{\circ} \mathrm{C}$ for $30 \mathrm{sec}$. The relative expression of each target gene was quantified using the $2^{-\Delta \Delta C q}$ method (16), with normalization using the level of $\beta$-actin.

Western blotting. The cells were lysed using RIPA buffer containing PMSF and phosphatase inhibitor (Beyotime
Institute of Biotechnology) on ice and protein concentration was measured using a BCA protein assay (Pierce; Thermo Fisher Scientific, Inc.). The proteins (20 $\mu \mathrm{g} / \mathrm{well})$ were separated via $10 \%$ SDS-PAGE, following which the protein samples were transferred onto a PVDF membrane (EMD Millipore), which was blocked with $5 \%$ low fat milk for $1 \mathrm{~h}$ and then incubated with the primary antibodies $(1: 1,000)$ at $4^{\circ} \mathrm{C}$ overnight. The following day, the membrane was incubated with secondary antibodies (1:1,000; cat. no. A0208 and A0216, Beyotime Institute of Biotechnology) for $1 \mathrm{~h}$ at room temperature and developed using ECL (Pierce; Thermo Fisher Scientific, Inc.). The target protein level was normalized to that of $\beta$-actin, and that of the phosphorylated target protein was normalized to that of the corresponding total protein.

Proliferation analysis. The WST-1 cell proliferation assay kit (Roche Diagnostics) and 5-ethynyl-2'-deoxyuridine (EdU) assay (RiboBio Co., Ltd.) were used to measure the proliferation of endothelial cells. The endothelial cells $\left(2 \times 10^{3}\right.$ cells/well $)$ were incubated with conditioned medium (CM) derived from the acute hypoxia or intermittent hypoxia-exposed HepG2 cells, in 96-well plates for 1-3 days. At different time points (24, 48 and $72 \mathrm{~h}$ ), WST-1 (10 $\mu \mathrm{l})$ was added, followed by measuring the absorbance at $450 \mathrm{~nm}$ using a microplate reader (Thermo Fisher Scientific, Inc.). For the EDU assays, the endothelial cells were incubated with EdU working solution $(50 \mu \mathrm{M})$ for $2 \mathrm{~h}$ at $37^{\circ} \mathrm{C}$, and then stained with Hoechst solution. Images were captured in six randomly selected fields and analyzed with an Olympus fluorescence microscope (Olympus Corporation). The experiments were performed in triplicate.

In vitro tube formation assay. The endothelial cells $\left(4 \times 10^{4}\right.$ cells/well $)$ were incubated with the $\mathrm{CM}$ derived from acute hypoxia or intermittent hypoxia-exposed HepG2 cells at $37^{\circ} \mathrm{C}$ for $4 \mathrm{~h}$ in 24 -well plates coated using Matrigel matrix (BD Biosciences). ImageJ software (National Institutes of Health) was used to quantify the number of tubes in three randomly selected fields that were observed with an Olympus fluorescence microscope (magnification, x100).

In vivo tumor angiogenesis. The protocols for animal experiments were reviewed and approved by the Ethical Committee on Animal Experiments of Animal Care Committee of Fudan University (Fudan, China). Male BALB/c nu/nu mice at 4-6 weeks of age weighing 18-20 g were obtained from SLAC Laboratory Animal Co., Ltd. Mice were housed in animal rooms with a 10 -h light/14-h dark cycle and at a constant temperature $\left(22-27^{\circ} \mathrm{C}\right)$. Animals had free access to standard rodent chow and water. Following exposure to acute or intermittent hypoxia, liver cancer cells $\left(2 \times 10^{7}\right)$ mixed with endothelial cells $\left(5 \times 10^{6}\right)$ were injected subcutaneously into the flanks of the mice (each group, $n=3$ ) for the evaluation of tumor angiogenesis. The immunohistologic staining of endothelial cells was subsequently performed. Briefly, subcutaneous tumors were fixed in $10 \%$ formaldehyde solution for $10 \mathrm{~h}$ at room temperature, embedded in paraffin and cut into $5 \mu \mathrm{m}$ thick slices. Some slices were stained with hematoxylin and eosin (H\&E; Beyotime Institute of Biotechnology) according to a standard procedure (17). For VEGF and CD31 detection, tissue slices were deparaffinized 
A
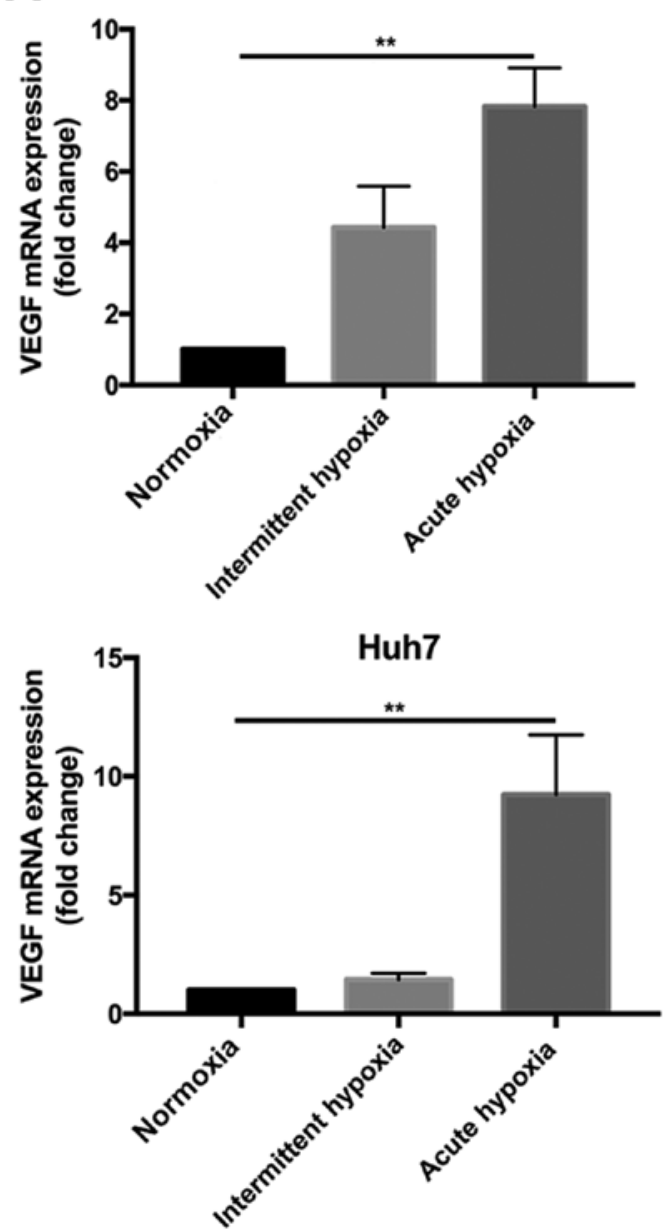

B

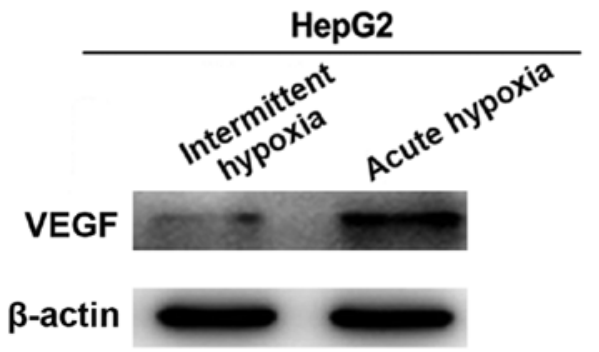

HepG2

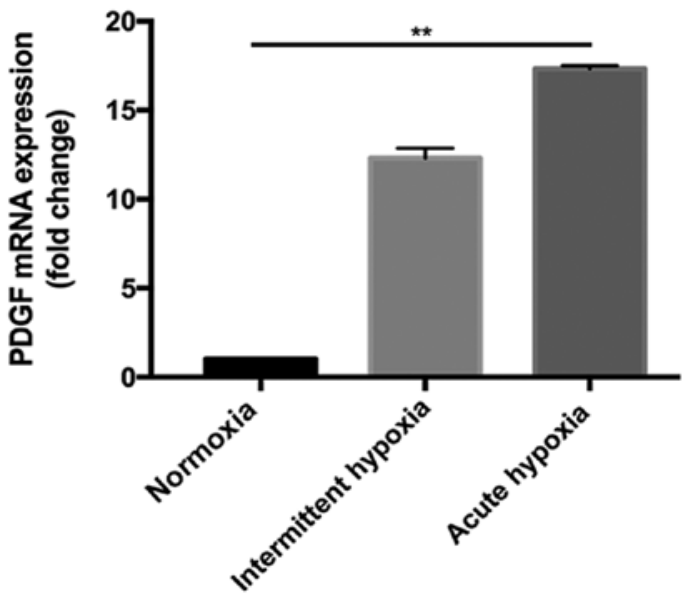

家

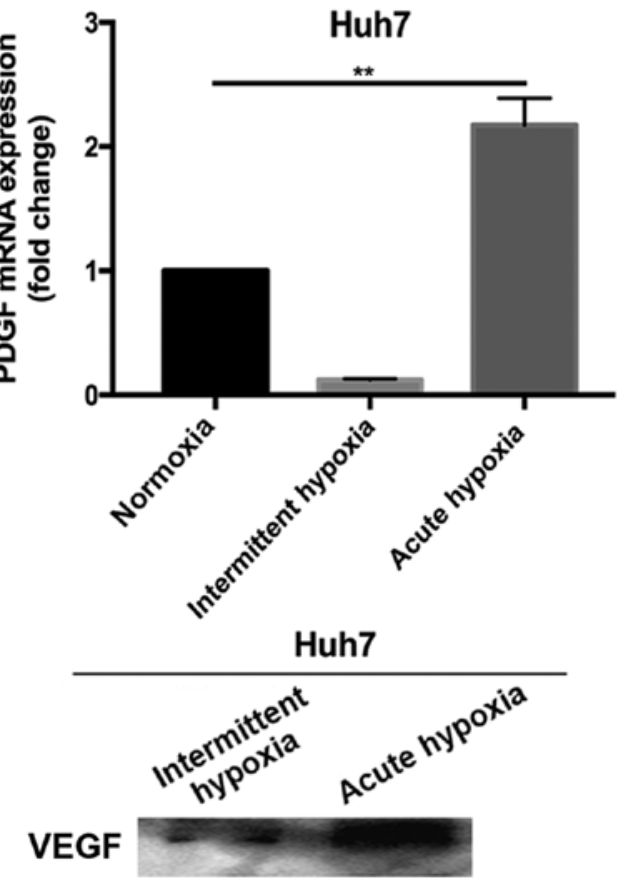

$\beta$-actin

Figure 1. Expression of VEGF in liver cancer cells under intermittent vs. acute hypoxia. (A) mRNA expression levels of VEGF and PDGF were measured using reverse transcription-quantitative polymerase chain reaction analysis in Huh7 and HepG2 cells under normoxia, or acute or intermittent hypoxia. (B) Protein expression levels of VEGF were markedly reduced in intermittent hypoxia-exposed Huh7 or HepG2 cells. ${ }^{* *} \mathrm{P}<0.01$. VEGF, vascular endothelial growth factor; PDGF, platelet-derived growth factor.

in xylene for $20 \mathrm{~min}$ at room temperature, rehydrated in gradient ethanol $(100,95,90$ and $80 \%)$ and treated with $0.3 \%$ $\mathrm{H}_{2} \mathrm{O}_{2}$ for $15 \mathrm{~min}$ at room temperature to block endogenous peroxidase activity. To retrieve the antigen, slices were heated in $10 \mathrm{mM}$ citrate buffer ( $\mathrm{pH}$ 6.0) in a microwave oven at $95^{\circ} \mathrm{C}$ three times for $5 \mathrm{~min}$. Slices were then blocked with $20 \%$ goat serum (Beyotime Institute of Biotechnology) for $30 \mathrm{~min}$ at room temperature, and were incubated with VEGF antibody (1:100; cat. no. ab51745; Abcam) or CD31 antibody (1:50; cat. no. ab28364; Abcam) at $4^{\circ} \mathrm{C}$ overnight and with the secondary antibody (1:50; cat. no. A0208, Beyotime Institute of Biotechnology) at room temperature for $30 \mathrm{~min}$. Slices were treated with 3,3'-diaminobenzidine tetrahydrochloride (DAB; Beyotime Institute of Biotechnology), counterstained with hematoxylin and visualized under an Olympus IX73 inverted microscope. The cellular brown staining was considered as positive reaction.

ROS measurement. The generation of ROS was quantified using 2',7'-dichlorodihydrofluorescein diacetate (DCFH-DA; Beyotime Institute of Biotechnology). Briefly, following acute hypoxia or intermittent hypoxia exposure, the liver cancer cells were incubated with serum-free media containing $10 \mu \mathrm{M}$ DCFH-DA fluorescent probe $30 \mathrm{~min}$ for at $37^{\circ} \mathrm{C}$ in the dark. The cells were then washed with serum-free DMEM three times to completely remove residual DCFH-DA, and fluorescence of the DCFH-DA-loaded cells was measured using a fluorescence plate reader. 

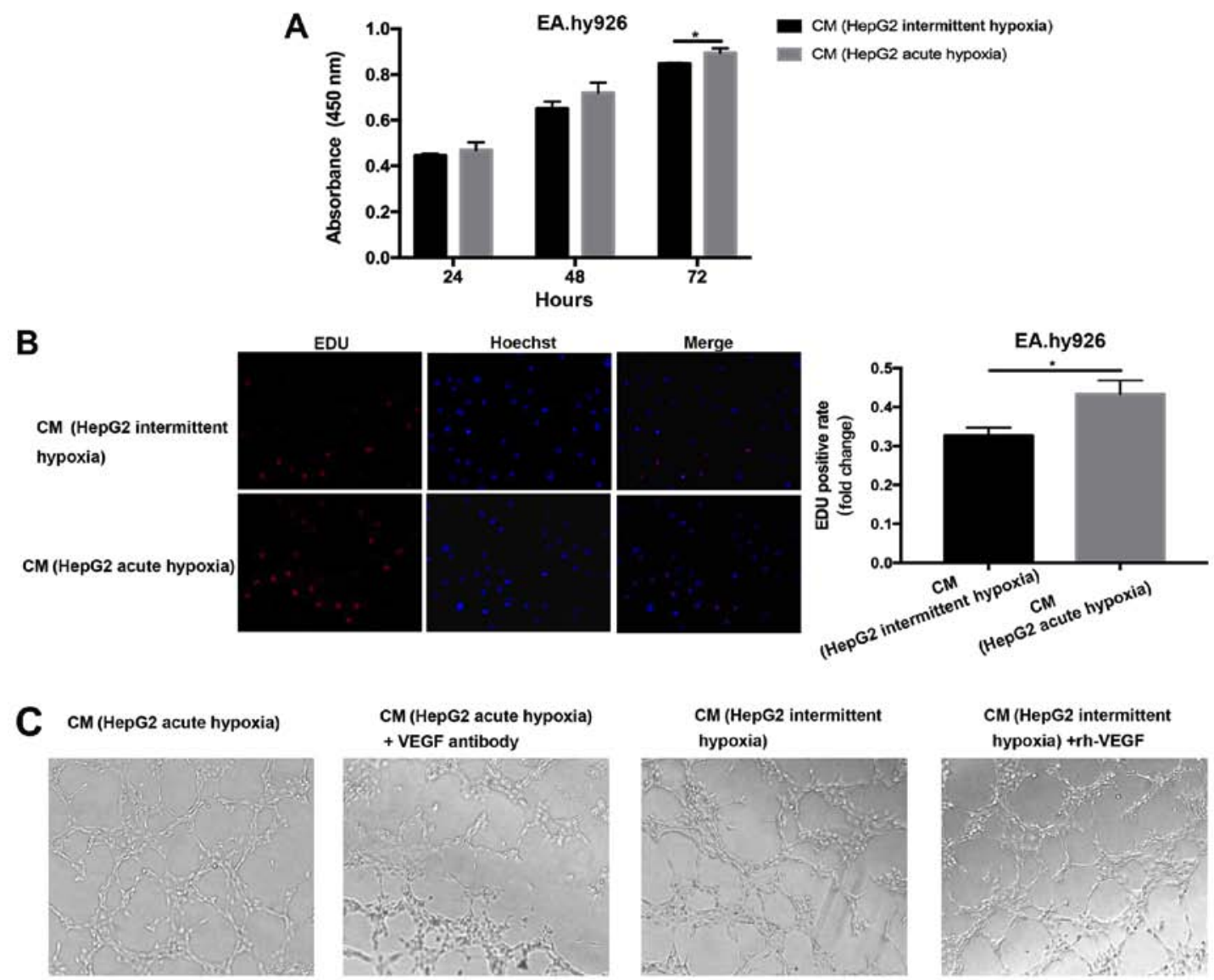

D
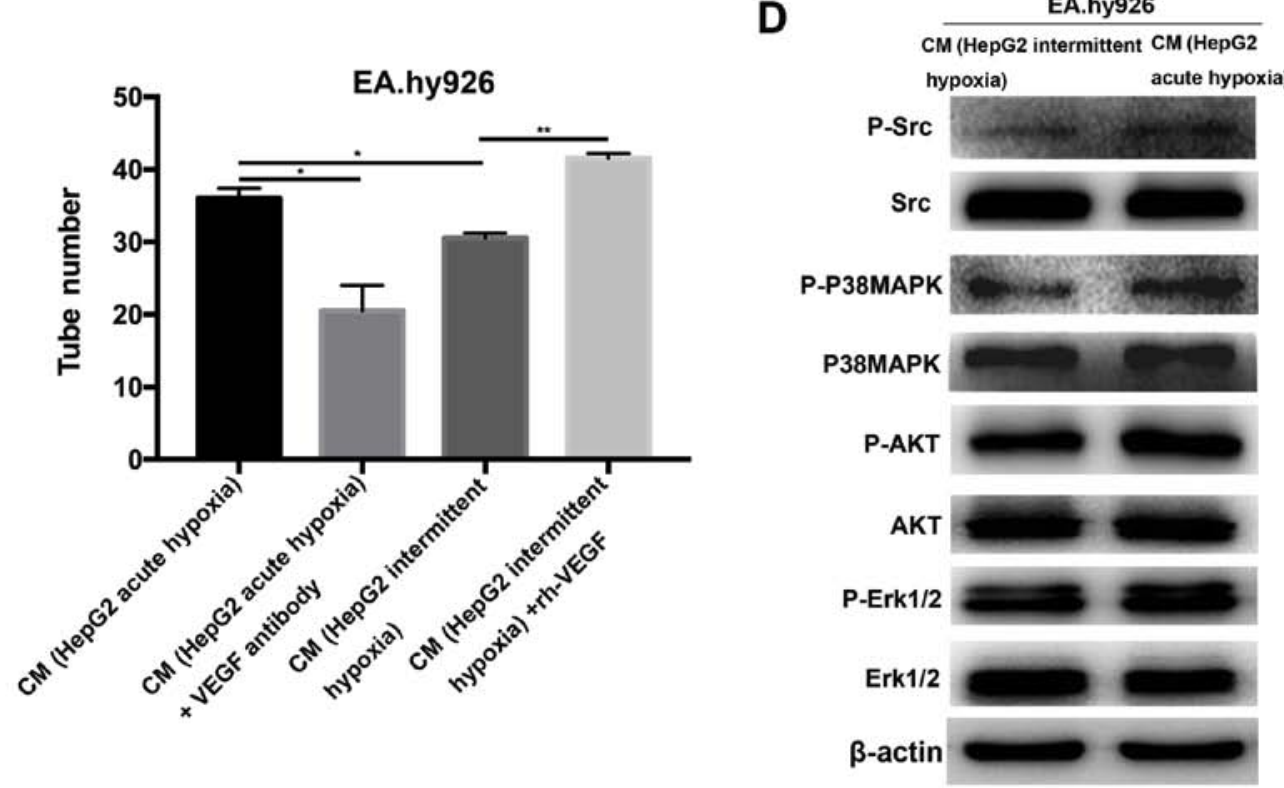

Figure 2. Effects of CM from intermittent or acute hypoxia-exposed HepG2 cells on endothelial cells. CM from acute hypoxia-exposed HepG2 markedly promoted the proliferation of endothelial cells, as detected using (A) WST-1 and (B) EdU assay (magnification, x200). (C) In vitro tube formation from endothelial cells cultured in CM from acute or intermittent hypoxia-exposed HepG2 with or without VEGF neutralizing antibody or rhVEGF (magnification, x100). (D) Activation of Src, p38MAPK, AKT and ERK1/2 pathways in endothelial cells cultured with CM from acute or intermittent hypoxia-exposed HepG2 cells was evaluated using western blotting. ${ }^{*} \mathrm{P}<0.05,{ }^{* *} \mathrm{P}<0.01$. CM, conditioned media; VEGF, vascular endothelial growth factor; rhVEGF, recombinant human VEGF; MAPK, mitogen-activated protein kinase; ERK, extracellular signal-regulated kinase; p-, phosphorylated; EdU, 5-ethynyl-2'-deoxyuridine.

The liver cancer cells were pre-treated with NAC (10 $\mathrm{mmol} / \mathrm{l}$, a ROS scavenger) for $30 \mathrm{~min}$ at $37^{\circ} \mathrm{C}$ to reduce intracellular ROS sources, and exposed to hypoxia for $24 \mathrm{~h}$. Images were captured with an Olympus fluorescence microscope at X200 magnification.
Statistical analysis. SPSS 13.0 software (SPSS, Inc.) was used for data analysis. All values are expressed as the means \pm standard deviation. Student's unpaired t-test and one-way analysis of variance were used to compare between two samples and among three groups, respectively. $\mathrm{P}<0.05$ 


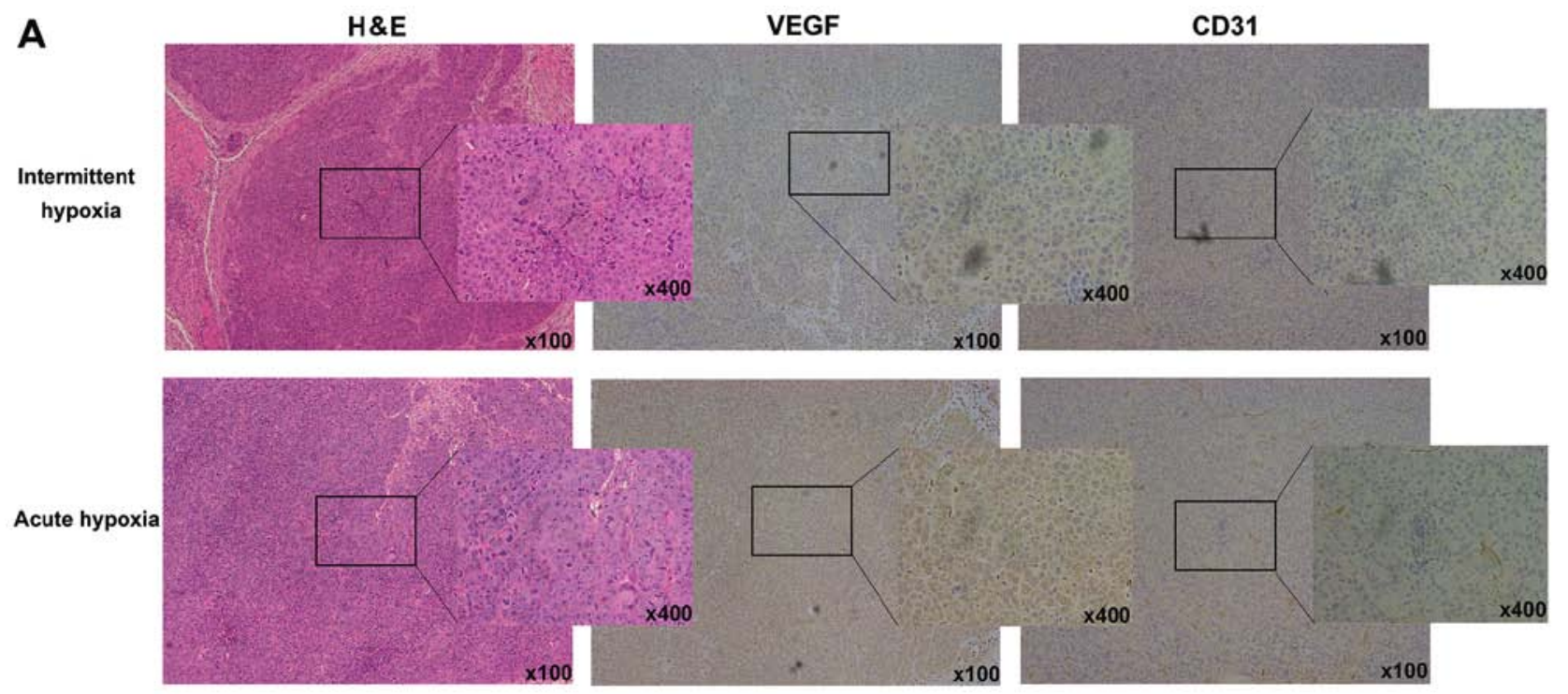

B
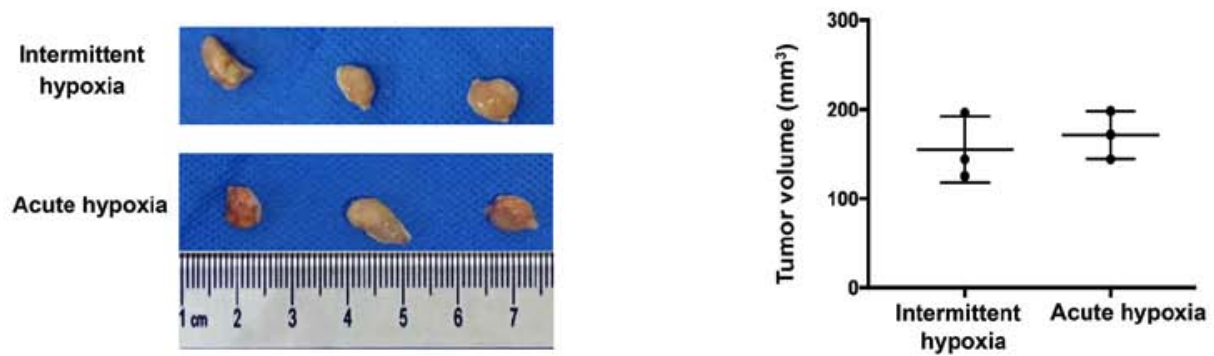

Figure 3. Effects of acute or intermittent hypoxia-exposed liver cancer cells on in vivo angiogenesis. Acute or intermittent hypoxia-exposed liver cancer cells $\left(2 \times 10^{7}\right)$ mixed with endothelial cells $\left(5 \times 10^{6}\right)$ were injected into the flanks of mice (each group, $\left.n=3\right)$. (A) Compared with the tumors arising from acute hypoxia-exposed liver cancer cells, less neovascularization (CD31 staining) and expression of VEGF were observed in tumors formed from intermittent hypoxia-exposed liver cancer cells, in the presence of endothelial cells. (B) No significant difference in size was observed between tumors arising from intermittent and acute hypoxia-exposed liver cancer cells co-inoculated with endothelial cells. VEGF, vascular endothelial growth factor.

was considered to indicate a statistically significant difference.

\section{Results}

Expression of VEGF is attenuated in liver cancer cells under intermittent hypoxia. The liver cancer cells were cultured under normoxia, or under acute hypoxia or intermittent hypoxia conditions. As shown using RT-qPCR analysis (Fig. 1A), the expression of VEGF in the acute and intermittent hypoxia-exposed liver cancer cells was significantly higher than that in the cells under normoxic conditions. However, the magnitude of this increase in the liver cancer cells exposed to intermittent hypoxia was significantly lower than that in the cells exposed to acute hypoxia. This was confirmed using western blotting (Fig. 1B). These results suggest that the expression of pro-angiogenic factor VEGF in liver cancer cells can be modulated by the patterns of hypoxia. In subsequent experiments, the biological effects of different hypoxic patterns (intermittent hypoxia vs. intermittent hypoxia) were compared. Although the mRNA expression of PDGF was also significantly increased in the acute hypoxia-exposed liver cancer cells, the effects of intermittent hypoxia on the expression of PDGF were inconsistent with those of normoxia in the two liver cancer cell lines (Fig. 1A). Therefore, the role of VEGF was investigated in the subsequent experiments.
Effects of CM from intermittent hypoxia- or acute hypoxia-exposed liver cancer cells on endothelial cell in vitro and in vivo. Subsequently, the effects of CM from acute or intermittent hypoxia-exposed liver cancer cells on angiogenesis were investigated.

In vitro cell proliferation (Fig. $2 \mathrm{~A}$ and $\mathrm{B}$ ) and tube formation (Fig. 2C) in endothelial cells cultured in CM from the intermittent hypoxia-exposed liver cancer cells were significantly reduced compared with those cultured in CM from acute hypoxia-exposed liver cancer cells. In parallel, activation of the Src, p38MAPK, AKT and ERK1/2 pathways was attenuated in the endothelial cells cultured in CM from intermittent hypoxia-exposed liver cancer cells (Fig. 2D).

Experiments were then performed to verify whether the pro-angiogenic effect of CM from acute hypoxia-treated liver cancer cells was due to VEGF. Therefore, the VEGF in the CM from hypoxia-exposed liver cancer cells was specifically neutralized. The removal of VEGF in the CM from acute hypoxia-exposed HepG2 cells using anti-VEGF neutralizing antibody resulted in a decrease in tube formation in endothelial cells (Fig. 2C). By contrast, the angiogenic response of tube formation in endothelial cells was increased when the endothelial cells were cultured in $\mathrm{CM}$ from intermittent hypoxia-exposed liver cancer cells supplemented with recombinant VEGF (Fig. 2C). These data confirmed that the pro-angiogenic effects of acute 

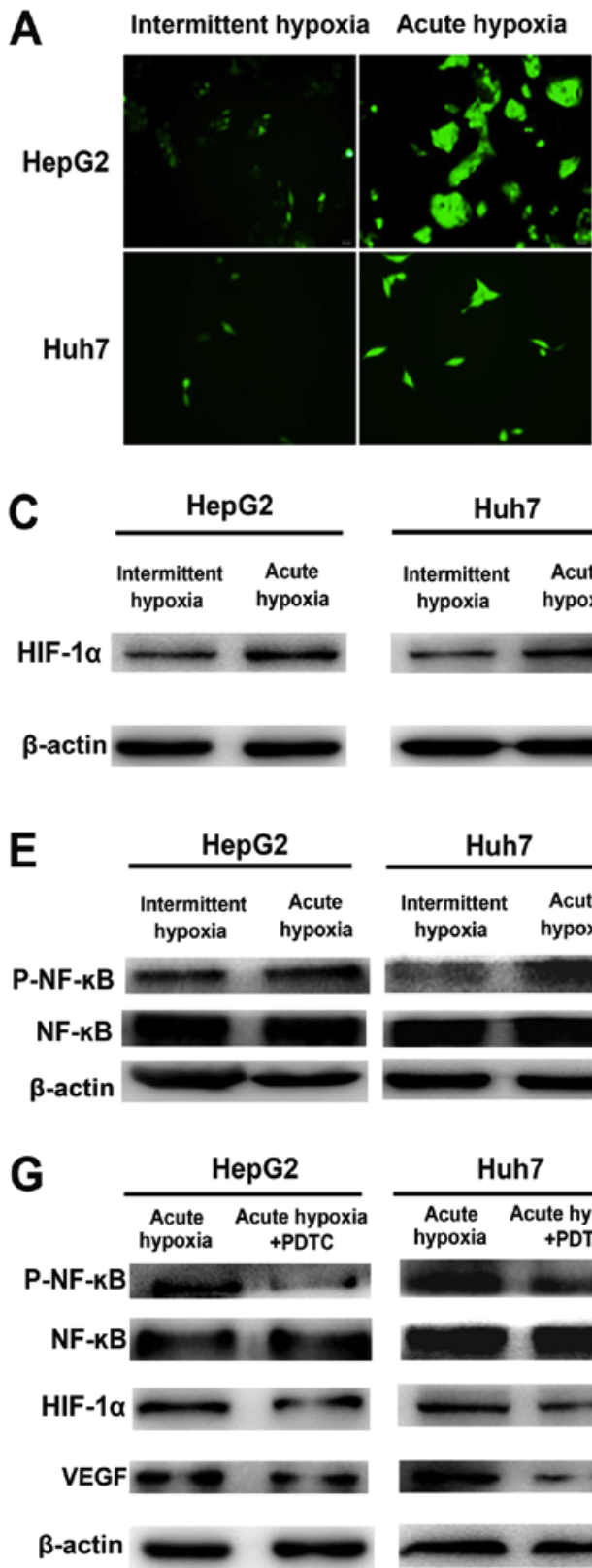
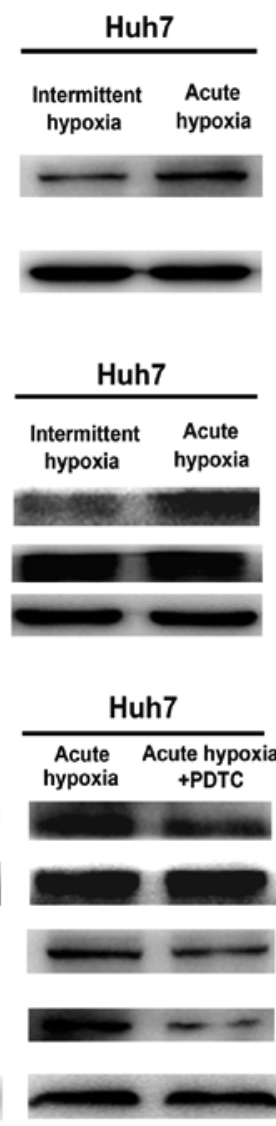

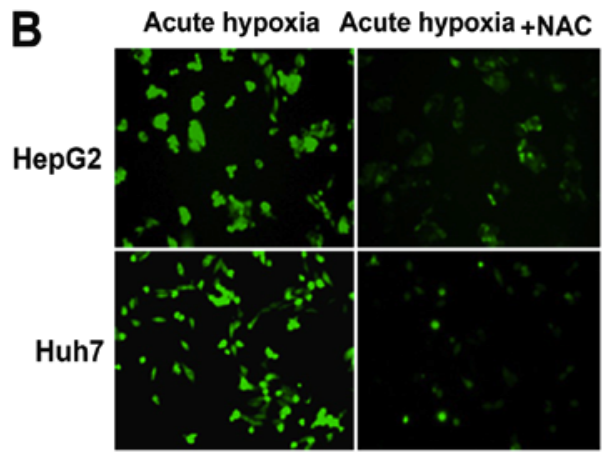

D
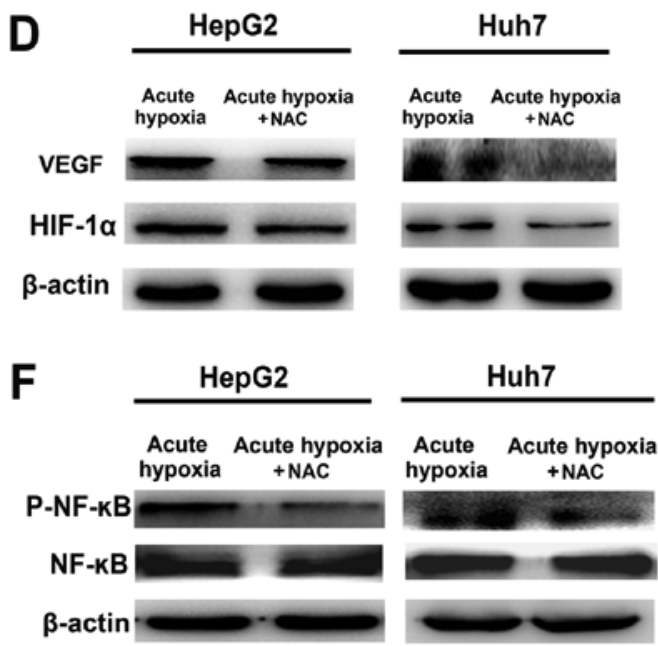

H

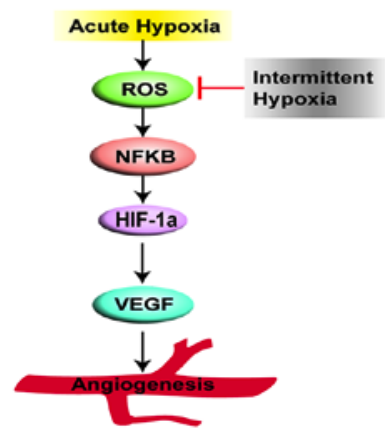

Figure 4. NF-kB-mediated activation of the ROS/HIF-1 $\alpha$ pathway is involved in the expression of VEGF in liver cancer cells under hypoxia. (A) Levels of intracellular ROS in acute and intermittent hypoxia-exposed liver cancer cells were measured using 2',7'-dichlorodihydrofluorescein diacetate (magnification, x200). (B) When acute hypoxia-exposed liver cancer cells were pre-cultured with NAC (a ROS scavenger), the level of intracellular ROS was significantly decreased (magnification, x200). (C) Expression of HIF-1 $\alpha$ in acute and intermittent hypoxia-exposed Huh7 and HepG2 cells. (D) In parallel with the ROS decrease, protein expression levels of HIF-1 $\alpha$ and VEGF were downregulated. (E) activity of NF- $\mathrm{kB}$ in acute and intermittent hypoxia-exposed liver cancer was measured using western blotting. (F) When acute hypoxia-treated liver cancer cells were pre-treated with NAC (a ROS scavenger), the phosphorylation of

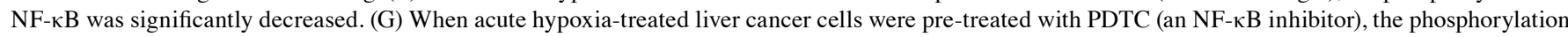
of NF-kB, and the expression of HIF-1 $\alpha$ and VEGF were significantly lower. $(\mathrm{H})$ Diagram illustrating the effect of intermittent hypoxia on alleviating the increase in VEGF and decreasing the pro-angiogenic potential of liver cancer cells. VEGF, vascular endothelial growth factor; ROS, reactive oxygen species; HIF-1 $\alpha$ hypoxia-inducible factorl $\alpha$; p-, phosphorylated. NAC, $\mathrm{N}$-acetyl-cysteine.

hypoxia-exposed liver cancer cells on in vitro angiogenesis were mediated through VEGF.

To investigate the effects of hypoxia-exposed liver cancer cells on in vivo angiogenesis, acute or intermittent hypoxia-exposed liver cancer cells mixed with endothelial cells were injected subcutaneously into nude mice and tumor neovascularization was examined. As visualized by VEGF and CD31 staining, tumors arising from intermittent hypoxia-exposed liver cancer cells exhibited lower neovascularization than those from acute hypoxia-exposed liver cancer cells (Fig. 3A), although tumor size did not differ significantly (Fig. 3B).

ROS/HIF-1 $\alpha$ pathway is responsible for the increased expression of VEGF in liver cancer under acute hypoxia. The ROS levels were assessed using DCFH-DA, as shown in Fig. 4A and B. The levels of intracellular ROS were significantly decreased in the intermittent hypoxia-exposed liver cancer cells compared with those in the acute hypoxia-exposed cells. Similarly, the expression of HIF-1 $\alpha$ was inhibited 
under intermittent hypoxia (Fig. 4C). To determine whether ROS was involved in the regulation of HIF-1 $\alpha$, the acute hypoxia-exposed liver cancer cells were pre-cultured with NAC, a ROS scavenger (Fig. 4B), and the increases in HIF-1 $\alpha$ and VEGF were significantly downregulated (Fig. 4D). These data indicated that acute hypoxia, with the sequential triggering of ROS accumulation and HIF-1 $\alpha$ pathway activation, may be involved in the increased expression of VEGF in liver cancer under acute hypoxia, and intermittent hypoxia may downregulate intracellular ROS levels and attenuate the expression of VEGF.

$N F-k B$ mediates the regulation of HIF-l $\alpha$ by ROS in acute hypoxia-exposed liver cancer cells. Previous studies have shown that $\mathrm{ROS}$ are involved in activating $\mathrm{NF}-\kappa \mathrm{B}$ pathways, enhancing the expression of HIF-1 $\alpha$ (18-22). To assess whether the upregulation of HIF- $1 \alpha$ induced by ROS was mediated through the NF- $\mathrm{BB}$ pathway, the activity of NF- $\kappa \mathrm{B}$ was measured under hypoxic conditions. As presented in Fig. 4E, the phosphorylation of $\mathrm{NF}-\kappa \mathrm{B}$ was significantly decreased in the intermittent hypoxia-exposed liver cancer cells compared with that in the cells exposed to acute hypoxia. Upon pre-treated with NAC to scavenge ROS, the phosphorylation of NF- $\mathrm{NB}$ in acute hypoxia-exposed liver cancer was significantly attenuated (Fig. 4F). The use of NF- $\kappa \mathrm{B}$ inhibitor PDTC significantly lowered the phosphorylation of NF- $\kappa \mathrm{B}$, and the expression of HIF- $1 \alpha$ and that of its downstream target VEGF in acute hypoxia-exposed liver cancer cells (Fig. 4G). These data indicate that activation of the ROS/NF- $\kappa \mathrm{B} / \mathrm{HIF}-1 \alpha$ pathway may be responsible for the increased expression of VEGF in liver cancer cells under acute hypoxia, and intermittent hypoxia may decrease ROS/NF- $\kappa \mathrm{B} / \mathrm{HIF}-1 \alpha$ activity to downregulate the expression of VEGF.

\section{Discussion}

In the present study, it was demonstrated that intermittent hypoxia attenuated the expression of VEGF in liver cancer cells compared with that in acute hypoxia. Secondly, it was shown that the pro-angiogenic effect of intermittent hypoxia-exposed liver cancer cells on endothelial cells was significantly reduced compared with that of acute hypoxia-exposed liver cancer cells. It is anticipated that these findings are of potential value in establishing a novel embolism strategy using TACE to improve treatment efficacy.

Due to its insidious onset, the majority of patients with liver cancer are diagnosed at the intermediate-advanced stage (23). TAE/TACE, which embolizes the tumor blood supply to cause tumor necrosis by inducing ischemia, provides a modest survival benefit to patients (3). Several studies have suggested that TACE causes hypoxia and stimulates angiogenesis via pro-angiogenic factors, including basic fibroblast growth factor (b-FGF) and VEGF $(9,24)$. Elevated levels of VEGF following TACE, which represent an unfavorable factor, indicate poor patient prognosis $(8,9)$. Therefore, inhibiting the increase of VEGF following TACE represents a potential therapeutic strategy to prevent the rebound of blood vessel formation, and this may offer promise in improving treatment outcomes. In the present study, it was hypothesized that the pattern of hypoxia can modulate the expression of VEGF in hypoxia-exposed liver cancer cells. The results demonstrate that intermittent hypoxia can alleviate the acute hypoxia-induced increase of VEGF, and decrease the pro-angiogenic potential of liver cancer cells; these findings may be of value in establishing a novel embolism strategy using TACE.

VEGF is the most potent angiogenic factor stimulating angiogenesis $(25,26)$. Acute hypoxia caused by TACE induces abnormal angiogenesis via an increase in VEGF levels. In the present study, it was shown that intermittent hypoxia attenuated the levels of VEGF in liver cancer cells compared with those in acute hypoxia. It has been reported that hypoxia (1\% hypoxia, $24 \mathrm{~h}$ ), in contrast to normoxia, impairs the angiogenic response of endothelial cells to VEGF stimulation (27). This suggests that, although different studies have used their own subtypes of hypoxia exposure, hypoxic exposure patterns can alter the neo-angiogenic process. The findings of the present study suggest that intermittent hypoxia can reduce the production of VEGF in liver cancer cells compared with that following acute hypoxia, and this may inform the design of an optimal embolism strategy using TACE. Embolization of the tumor feeding artery to a sub-stasis (intermittent hypoxia-like condition) may be better than occlusion of an arterial vessel to complete stasis (severe acute hypoxia). Therefore, specific embolism patterns using TACE therapy to induce intermittent hypoxia may be beneficial in liver cancer treatment.

Previous reports have shown that the increased activities of HIF- $1 \alpha$ and NF- $\kappa$ B are mainly mediated by ROS in cells under hypoxia, and the transcription of HIF-1 $\alpha$ is enhanced following $\mathrm{NF}-\kappa \mathrm{B}$ activation $(18,21)$. In the present study, it was shown that the expression of VEGF was significantly increased in liver cancer cells under acute hypoxia, which was mediated via the activation of ROS/NF- $\kappa \mathrm{B} / \mathrm{HIF}-1 \alpha$ signaling, whereas intermittent hypoxia decreased ROS/NF- $\kappa \mathrm{B} / \mathrm{HIF}-1 \alpha$ activity and downregulated the expression of VEGF. This suggests that the expression of VEGF in liver cancer cells under hypoxia is modulated by ROS/NF- $\kappa \mathrm{B} / \mathrm{HIF}-1 \alpha$ signaling, although this does not exclude the possibility that ROS increase the activity of HIF-1 $\alpha$ through the stability of HIF-1 $\alpha$ via inactivation of proline hydroxylase, as previously described (28).

Taken together, the present study showed that in vitro and in vivo angiogenesis was attenuated when endothelial cells were cultured in CM from intermittent hypoxia-exposed liver cancer cells or co-inoculated with intermittent hypoxia-exposed liver cancer cells in mice, respectively. This was correlated with reduced levels of VEGF in intermittent hypoxia-exposed liver cancer cells.

The present study has a number of limitations. First, although it was found that VEGF was markedly upregulated in liver cancer cells exposed to acute hypoxia, this does not exclude the possibility that other pro-angiogenic factors, including PDGF and b-FGF, secreted from acute hypoxia-exposed liver cancer cells promote neo-angiogenesis. Second, the effects of hypoxia on the biological characteristics of liver cancer cells themselves were not examined. It has been reported that intermittent hypoxia promotes more malignant biological behaviors of breast cancer cells $(29,30)$. Therefore, it is possible that liver cancer cells present more malignant behaviors under intermittent 
hypoxia. Third, an ideal TACE animal model is required to validate the effect of the proposed novel embolism pattern, inducing intermittent hypoxia, on increasing the efficacy of liver cancer treatment.

In conclusion, as presented in Fig. $4 \mathrm{H}$, the present study demonstrated that intermittent hypoxia alleviates the increase in VEGF levels and reduces the consequent pro-angiogenic potential of liver cancer cells induced by acute hypoxia, suggesting a novel treatment strategy.

\section{Acknowledgements}

Not applicable.

\section{Funding}

This study was funded by the National Natural Science Foundation of China (grant no. 81272723).

\section{Availability of data and materials}

The datasets used and/or analyzed during the current study are available from the corresponding author on reasonable request.

\section{Authors' contributions}

RXC, JFC and ZGR designed the study and analyzed the data. GD, XHL, HHL and DMG performed the experiments. GD, RXC, JFC and ZGR wrote and revised the manuscript. All authors read and approved the final manuscript.

\section{Ethics approval and consent to participate}

The protocols for animal experiments were reviewed and approved by the Ethical Committee on Animal Experiments of Animal Care Committee of Fudan University (Fudan, China).

\section{Patient consent for publication}

Not applicable.

\section{Competing interests}

The authors declare that they have no competing interests.

\section{References}

1. Chua CW and Choo SP: Targeted therapy in hepatocellular carcinoma. Int J Hepatol 2011: 1-11, 2011.

2. Zhang ZM, Guo JX, Zhang ZC, Jiang N, Zhang ZY and Pan LJ: Therapeutic options for intermediate-advanced hepatocellular carcinoma. World J Gastroenterol 17: 1685-1689, 2011.

3. Huang YH, Wu JC, Chen SC, Chen CH, Chiang JH, Huo TI, Lee PC, Chang FY and Lee SD: Survival benefit of transcatheter arterial chemoembolization in patients with hepatocellular carcinoma larger than $10 \mathrm{~cm}$ in diameter. Aliment Pharmacol Ther 23: $129-135,2006$

4. Guan YS, He Q and Wang MQ: Transcatheter arterial chemoembolization: History for more than 30 years. ISRN Gastroenterol 2012: 480650, 2012.

5. Pleguezuelo M, Marelli L, Misseri M, Germani G, Calvaruso V, Xiruochakis E, Manousou P and Burroughs AK: TACE versus TAE as therapy for hepatocellular carcinoma. Expert Rev Anticancer Ther 8: 1623-1641, 2008.
6. Zhang Y and Lai Y: A combination of anti-angiogenesis with endostatin and transcatheter arterial chemoembolization (TACE) enhances antitumour effects in a rabbit VX2 liver tumor. Radiol Soc North Am 2010 Sci Assembly Meeting, 2010.

7. Hanks BA, Suhocki PV, DeLong DM, Doan PL, Liu E, Tsai AL, Burke CT, Bernard SA, O'Neil BH and Morse MA: The efficacy and tolerability of transarterial chemo-embolization (TACE) compared with transarterial embolization (TAE) for patients with unresectable hepatocellular carcinoma (HCC). J Clin Oncol 26: 4595, 2008.

8. Sergio A, Cristofori C, Cardin R, Pivetta G, Ragazzi R, Baldan A, Girardi L, Cillo U, Burra P, Giacomin A and Farinati F: Transcatheter arterial chemoembolization (TACE) in hepatocellular carcinoma (HCC): The role of angiogenesis and invasiveness. Am J Gastroenterol 103: 914-921, 2008.

9. Chao Y, Wu CY, Kuo CY, Wang JP, Luo JC, Kao CH, Lee RC, Lee WP and Li CP: Cytokines are associated with postembolization fever and survival in hepatocellular carcinoma patients receiving transcatheter arterial chemoembolization. Hepatol Int 7: 883-892, 2013.

10. Jia ZZ, Jiang GM and Feng YL: Serum HIF-1alpha and VEGF levels pre- and post-TACE in patients with primary liver cancer. Chin Med Sci J 26: 158-162, 2010.

11. Liu K, Min XL, Peng J, Yang K, Yang L and Zhang XM: The changes of HIF-1 $\alpha$ and VEGF expression after TACE in patients with hepatocellular carcinoma. J Clin Med Res 8: 297-302, 2016.

12. Jia ZZ, Jiang GM and Feng YL: Serum HIF-1alpha and VEGF levels pre- and post-TACE in patients with primary liver cancer. Chin Med Sci J 26: 158-162, 2011.

13. Britten CD, Gomes AS, Wainberg ZA, Elashoff D, Amado R, Xin Y, Busuttil RW, Slamon DJ and Finn RS: Transarterial chemoembolization plus or minus intravenous bevacizumab in the treatment of hepatocellular cancer: A pilot study. BMC Cancer 12: 16, 2012.

14. Pinter M, Ulbrich G, Sieghart W, Kölblinger C, Reiberger T, Li S, Ferlitsch A, Müller C, Lammer J and Peck-Radosavljevic M: Hepatocellular carcinoma: A phase II randomized controlled double-blind trial of transarterial chemoembolization in combination with biweekly intravenous administration of bevacizumab or a placebo. Radiology 277: 903-912, 2015.

15. Jin B, Wang D, Lewandowski RJ, Riaz A, Ryu RK, Sato KT, Larson AC, Salem R and Omary RA: Chemoembolization endpoints: Effect on survival among patients with hepatocellular carcinoma. AJR Am J Roentgenol 196: 919-928, 2011.

16. Livak KJ and Schmittgen TD: Analysis of relative gene expression data using real-time quantitative PCR and the 2(-Delta Delta C(T)) method. Methods 25: 402-408, 2001.

17. Lu D,Liao Y,Zhu SH, Chen QC, Xie DM,Liao JJ,Feng X, Jiang MH and $\mathrm{He} \mathrm{W}$ : Bone-derived Nestin-positive mesenchymal stem cells improve cardiac function via recruiting cardiac endothelial cells after myocardial infarction. Stem Cell Res Ther 10: 127, 2019.

18. Liu M, Ning X, Li R, Yang Z, Yang X, Sun S and Qian Q: Signalling pathways involved in hypoxia-induced renal fibrosis. J Cell Mol Med 21: 1248-1259, 2017.

19. Rius J, Guma M, Schachtrup C, Akassoglou K, Zinkernagel AS, Nizet V, Johnson RS, Haddad GG and Karin M: NF-kappaB links innate immunity to the hypoxic response through transcriptional regulation of HIF-1alpha. Nature 453: 807-811, 2008.

20. Huang Q, Zhan L, Cao H, Li J, Lyu Y, Guo X, Zhang J, Ji L, Ren T, An J, et al: Increased mitochondrial fission promotes autophagy and hepatocellular carcinoma cell survival through the ROS-modulated coordinated regulation of the NFKB and TP53 pathways. Autophagy 12: 999-1014, 2016.

21. Bonello S, Zähringer C, BelAiba RS, Djordjevic T, Hess J, Michiels C, Kietzmann T and Görlach A: Reactive oxygen species activate the HIF-1alpha promoter via a functional NFkappaB site. Arterioscler Thromb Vasc Biol 27: 755-761, 2007.

22. Diebold I, Djordjevic T, Hess J and Görlach A: Rac-1 promotes pulmonary artery smooth muscle cell proliferation by upregulation of plasminogen activator inhibitor-1: Role of NFkappaB-dependent hypoxia-inducible factor-1alpha transcription. Thromb Haemost 100: 1021-1028, 2008.

23. El-Halawany MS, Ismail HM, Zeeneldin AA, Elfiky A, Tantawy M, Kobaisi MH, Hamed I and Abdel Wahab AH: Investigating the pretreatment miRNA expression patterns of advanced hepatocellular carcinoma patients in association with response to TACE treatment. Biomed Res Int 2015: 649750, 2015.

24. Petrillo M,Patella F, Pesapane F, Suter MB, Ierardi AM, Angileri SA, Floridi C, de Filippo M and Carrafiello G: Hypoxia and tumor angiogenesis in the era of hepatocellular carcinoma transarterial loco-regional treatments. Future Oncol 14: 2957-2967, 2018. 
25. Ahluwalia A, Jones MK, Matysiak-Budnik T and Tarnawski AS: VEGF and colon cancer growth beyond angiogenesis: Does VEGF directly mediate colon cancer growth via a non-angiogenic mechanism? Curr Pharm Des 20: 1041-1044, 2014.

26. Petersen W, Pufe T, Stärke C, Fuchs T, Kopf S, Neumann W, Zantop T, Paletta J, Raschke M and Becker R: The effect of locally applied vascular endothelial growth factor on meniscus healing: Gross and histological findings. Arch Orthop Trauma Surg 127: 235-240, 2007.

27. Olszewska-Pazdrak B, Hein TW, Olszewska P and Carney DH: Chronic hypoxia attenuates VEGF signaling and angiogenic responses by downregulation of KDR in human endothelial cells. Am J Physiol Cell Physiol 296: C1162-C1170, 2009.

28. Lee G, Won HS, Lee YM, Choi JW, Oh TI, Jang JH, Choi DK, Lim BO, Kim YJ, Park JW, et al: Oxidative dimerization of PHD2 is responsible for its inactivation and contributes to metabolic reprogramming via HIF-1 $\alpha$ activation. Sci Rep 6: 18928, 2016.
29. Chen A, Sceneay J, Gödde N, Kinwel T, Ham S, Thompson EW, Humbert PO and Möller A: Intermittent hypoxia induces a metastatic phenotype in breast cancer. Oncogene 37: 4214-4225, 2018.

30. Louie E, Nik S, Chen JS, Schmidt M, Song B, Pacson C, Chen XF, Park S, Ju J and Chen EI: Identification of a stem-like cell population by exposing metastatic breast cancer cell lines to repetitive cycles of hypoxia and reoxygenation. Breast Cancer Res 12: R94, 2010

(7)(9) This work is licensed under a Creative Commons Attribution-NonCommercial-NoDerivatives 4.0 International (CC BY-NC-ND 4.0) License. 